\title{
Curcumin Inhibits Heat-Induced Apoptosis by Suppressing NADPH Oxidase 2 and Activating the Akt/mTOR Signaling Pathway in Bronchial Epithelial Cel
}

\author{
Yuan Penga Junliang $\mathrm{Pu}^{\mathrm{b}}$ Chengyong Tang ${ }^{\mathrm{c}}$ Zhongjun $\mathrm{Wu}^{\mathrm{b}}$ \\ aThe first clinical college of Chongqing Medical University, Chong \\ Surgery, the First Affiliated Hospital of Chongqing Medical Universi \\ Clinical Pharmacology, the First Affiliated Hospital of Chongqing Me \\ Key Words

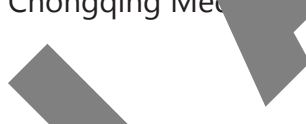

Curcumin $\bullet$ Heat $\cdot$ Apoptosis $\cdot$ NADPH Oxidase

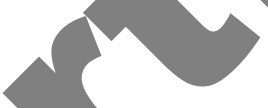
Abstract
Background: Heat causes bronchial
contributing to airway damage during the effect of curcumin on inhibit a po suppresses heat-induced apopt Methods: Bronchial epithelial ctr $1{ }^{\prime} \mathrm{HBE} 140$ cells were incubated at either $42{ }^{\circ} \mathrm{C}, 47^{\circ} \mathrm{C}$, $52{ }^{\circ} \mathrm{C}$, or $57^{\circ} \mathrm{C}$ for 5 mir a cel cubator and then returned back to normal culture conditions $\left(37^{\circ} \mathrm{C}\right)$. An in $O$ the hal inhalation injury rat model was established with a heat gun blowing hot air into air $y$ of rats. $16 \mathrm{HBE} 140$ cells and lung tissue were obtained for further study with tho cumin treatment. Cell viability was determined by measuring the absorbance of 5-dimethylthiazol-2-yl)-2,5-diphenyltetrazolium bromide (MTT). $2^{\prime}, 7^{\prime}$-dichloroflu ier eir vacetate fluorescence was used as a measure of reactive oxygen species (RA pro on. Levels of Bcl2, Bax, $\alpha$-ATP, cleaved Poly (ADP-ribose) polymerase (PARP), C $\quad$ caspase-3, gp91 ${ }^{\text {phox }}, \mathrm{p} 47^{\text {phox }}, \mathrm{p} 67^{\text {phox }}, \mathrm{p} 22^{\text {phox }}, \mathrm{p} 40^{\text {phox }}$, and Rac were determined by ing. TUNEL staining was used to determine apoptosis. Results: Heat treatment tric the apoptosis of $16 \mathrm{HBE} 140$ cells as shown by the increase in apoptosis molecular marker ding Bcl-2, Bax, cleaved PARP, and cleaved caspase-3. Administration of curcumin s. Iicantly inhibited apoptosis of $16 \mathrm{HBE} 140$ cells and suppressed the membrane translocation 1) PPH oxidase 2 cytosolic components, as well as ROS production. Downregulation of Akt nTOR phosphorylation induced by heat was also reversed by curcumin. Furthermore, we uemonstrated that NADPH oxidase 2 is upstream of Akt/mTOR in heat-induced apoptosis. The protective role of curcumin on bronchial epithelia apoptosis was also confirmed in vivo by a rat inhalation injury model. Conclusion: This study demonstrates that one of the critical mechanisms underlying curcumin inhibiting heat-induced apoptosis is through suppressing NADPH Oxidase 2 and activating the Akt/mTOR signaling pathway in bronchial epithelial cells. 


\section{Cellular Physiology and Biochemistry Published ontine: April19, $2017 \quad \begin{aligned} & \text { DOI: 10.1159/000475444 } 2017 \text { The Author(s). Published by S. Karger AG, Basel } \\ & \text { www.karger.com/cpb }\end{aligned}$ \\ Peng et al.: Curcumin Alleviates Heat-Induced Apoptosis of 16HBE140 Cells In Vitro and In Vivo}

\section{Introduction}

Thermal inhalation injury is a common concurrent injury in burn patients and is associated with significant longstanding pulmonary dysfunction and mortality [1]. Previous studies have suggested that bronchial epithelial cells are early targets of thermal inhalation injury [2]. Most studies have focused on the bronchial epithelial inflammation induce by chemical smoke or heat, ignoring that heat can also induce cell apoptosis and death, contributing to the inhalation injury [3]. Heat is a major extracellular stimulus that causes cellular oxidative stress and apoptosis [4]. However, the pathogenesis of heat-ind bronchial epithelia apoptosis remains largely unknown.

Overproduction of reactive oxygen species (ROS) triggers cell apoptosis th ugh signaling cascades $[5,6]$. Nicotinamide adenine dinucleotide phosphate (NADPF vid. the primary source of superoxide production and consists of two subunit he hrane (p22phox and gp91phox) and four subunits in the cytoplasm (p47phox, p ox, p. phox, and Rac). Upon activation, the cytoplasmic subunits translocate to the and combine with the membrane subunits to trigger NADPH oxidase act ${ }^{\wedge}$ [7]. In we present study, we aim to determine whether ROS derived from NADPH oxidas involved in heatinduced apoptosis of bronchial epithelial cells both in vitre

Akt, aserine/threoninekinase, playsanimportantrolein thys pathophysiological changes [8]. An increasing number of studies have repo amphosphorylated Akt prevents cells from undergoing apoptosis, which is regulate ROS [9]. The mammalian target of rapamycin (mTOR) serves as a centr gulator of apoptosis by integrating both intracellular and extracellular signals. Dis ies over the last decade have shown that the Akt/mTOR pathway is significantly ass an ith cell apoptosis [8]. Currently the relationship between NADPH oxidase, ROS an $t / m$ after heat treatment is not clear.

Curcumin, an active polyphenol deriv fro zomes of Curcuma longa, is reported to have antioxidant and anti-apoptotic ec 10]. Recent studies have indicated that longterm curcumin administration signific nic its oxidative stress and apoptosis in human neuroblastoma cells [11]. Curcl as ported to regulate the PKC $\delta / N A D P H$ oxidase/ ROS and Akt/mTOR signaling $\mathrm{p}$ vs in cancer cells $[12,13]$. However, whether curcumin regulates NADPH oxidase/ROS or t. /mTOR signaling pathway after heat treatment and the underlying mechanis e prorly understood.

In the present study e hyp hesized that curcumin suppressed heat-induced apoptosis by regulating NADPH/RT e Akt/mTOR signaling pathway.

\footnotetext{
al $\mathrm{d}$, f $4 \mathrm{~h}$ before or $1 \mathrm{~h}$ after the heat treatment. In some circumstances, DPI (10 $\mu \mathrm{m}$ Sigma-Aldrich,

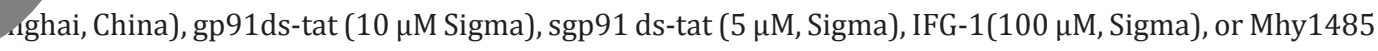
( $50 \mu \mathrm{M}$, Sigma) were added $4 \mathrm{~h}$ before the heat treatment.
}

\section{Animals and thermal inhalation injury}

All procedures were approved by the Animal Ethical Committee of Chongqing Medical University and were carried out in accordance with the approved guidelines. The thermal inhalation injury model was carried out as previously described [15]. Curcumin (10 mg/kg body weight) was administered intragastrically two days before the thermal inhalation and administered twice daily after the surgery. Both the model and sham groups were given a gavage of distilled water at the same volume as the drug.

\section{KARGER}


Cell viability assay

Cell viability was determined by measuring the absorbance of 3-(4,5-dimethylthiazol-2-yl)-2,5diphenyltetrazolium bromide (MTT) in living cells in accordance with the manufacturer's instructions [16]. Briefly, cells were seeded into 96 -well microtiter plates containing $100 \mu \mathrm{L}$ of medium at the previously described temperatures $\left(37^{\circ} \mathrm{C}, 42^{\circ} \mathrm{C}, 47^{\circ} \mathrm{C}, 52^{\circ} \mathrm{C}\right.$, and $\left.57^{\circ} \mathrm{C}\right)$ for $5 \mathrm{~min}$. Then, the cells were harvested at 12 h, 1 day, 2 days, and 5 days after treatment, and $10 \mu \mathrm{L}$ of $5 \mathrm{mg} / \mathrm{mL}$ MTT (Thermo Fisher Scientific, Fremon USA) was added to the medium in each well. The plates were incubated for an additional $4 \mathrm{~h}$ at $37^{\circ} \mathrm{C}$. After $\mathrm{h}$, the medium was discarded, and $100 \mu \mathrm{L}$ of acid isopropanol was added to dissolve the formazan product. The absorbance at $540 \mathrm{~nm}$ was measured by a Bio-Tek EPOCH Microplate Reader (Bio-Tek Instrument USA).

\section{Oxidative stress determination}

To evaluate the ROS production, 2',7'-dichlorofluorescein diacetate (DCF-DA) Scientific, Fremont, USA) was used to measure the changes in ROS levels [17]. Briefly, , ed in glass-bottomed dishes and incubated with $5 \mu \mathrm{mol} / \mathrm{L} \mathrm{H} 2 \mathrm{DCFDA}$ in the dark for $30 \mathrm{mi}$ a thrice times with pre-warmed PBS and then resuspended in PBS. The relative 1 of fluowocence were determined by confocal microscopy at the excitation wavelength of $488 \mathrm{~nm}$ and en $\quad$ n wavelength of 525 $\mathrm{nm}$. Images were obtained at 10 frames per second using a $4 \times$ obje $\quad 1 n \mathrm{~nm}$. Adroxynonenal and nitrotyrosine ELISA Kits were purchased from Cell Biolabs, Inc. ( $S$ ies $A$ ) and used according to the manufacturer's instructions. The data were normalized by performed in triplicate.

Preparation of the membrane fraction

To separate the cellular membrane, cells were ly HEPES (7.4), $10 \mathrm{mM} \mathrm{KCl}, 1.5 \mathrm{mM} \mathrm{MgCl}_{2}, 1 \mathrm{mM}$ EDTA, HEPES (7.4), $10 \mathrm{mM} \mathrm{KCl,} 1.5 \mathrm{mM} \mathrm{MgCl}_{2}, 1 \mathrm{mM}$ EDTA, a $1 \mathrm{ml}$. The cell membrane was separated by ultracentrifugation at $100,000 \mathrm{~g}$ for $2 \mathrm{~h}$. The mem was obtained by suspending the pellet with RIPA lysis buffer.

\section{Western blot analysis}

16HBE140 cells were harvest then lysed in RIPA buffer containing a mixture of protease inhibitors (Thermo Scientific, Framont, he lung tissue was collected at different time points and washed with PBS three times. a wots of therung lysates (30 $\mu$ g protein/well) and cell lysates (20 $\mu$ g protein/ well) were separated on 4- $\%$ Bis s gels. Western blotting was carried out as previously described [15]. Antibodies against $\mathrm{Bcl} 2$, P, cleaved PARP, cleaved caspase-3, gp91 $1^{\text {phox }}, \mathrm{p} 47^{\text {phox }}, \mathrm{p} 67^{\text {phox }}, \mathrm{p} 22^{\text {phox }}$, p40 phox , and Rac we taincu Irom Abcam (Cambridge, MA, USA). Antibodies against phosphorylated Akt (Thr308), pho no to kt (Ser473), phosphorylated mTOR (Ser2448), and phosphorylated mTOR (Ser2481) we purc'ed rom Cell Signaling Technology (Danvers, MA, USA). The antibody against PDK1 was purch from 1 (Montgomery, TX, USA).

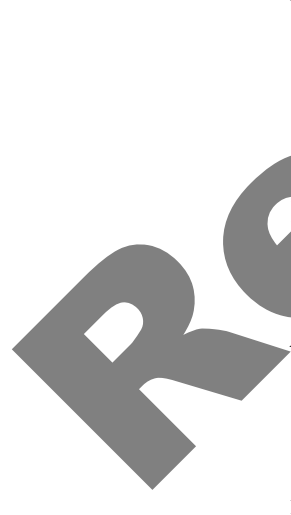

$\checkmark A$ tra

alls were transfected with a final siRNA concentration of 200 pM using Lipofectamine reas (Invitrogen, CA, USA) according to the manufacturer's protocol. The target sequence for the $\mathrm{N}^{\dagger}$ L- - oecific SiRNA was CCAUCCACACAAUUGCACAUCUCUU. Two days after transfection, the cells were ser or the experiment. As described previously [18], RT-PCR was performed to test the Nox2 mRNA ession. Nox2 primers were as follows: forward primer: ACTTCTTGGGTCAGCACTGG; reverse primer: ATTCCTGTCCAGTTGTCTTCG.

\section{TUNEL assay}

16HBE140 cells from different conditions were seeded on coverslips for one day. In brief, the cells were fixed and then stained with a terminal-deoxynucleotidyl transferase-dUTP nick end-labeling (TUNEL) assay (Invitrogen, CA, CA). Nuclei were counterstained with DAPI $(1 \mu \mathrm{g} / \mathrm{ml}$ ) (Thermo Fisher Scientific, MA, USA). Fluorescence signals were detected with an Axioplan microscope (Zeizz, Shanghai, China) equipped with an AxioCam HRm digital camera. The lung tissue sections (10 $\mu \mathrm{m}$ thick) were fixed, embedded and stained with the transferase-mediated dUTP nick-end labeling (TUNEL) technique using an apoptosis detection kit 
(Promega, WI, USA) according to the manufacturer's instruction. The positive cells were counted on 10 random sections. The number of positive stained cells was expressed as a percentage of the total number of cells counted in the 10 tissue sections.

\section{Statistics}

Statistical analysis was performed using Graphpad prism (Version 6; CA, USA) a Student's t test, on way analysis of variance (ANOVA) and the least significant difference (LSD) test. The data are presented a the mean \pm standard deviation (SD) of three independent experiments for each group. All tests were two tailed, and the level of significance was set at $\mathrm{P}<0.05$.

\section{Results}

Heat inhibited cell viability and induced apoptosis in $16 H B E 140$ cells

To test the effect of different temperatures on the $16 \mathrm{HBE} 140$ incubated at $37^{\circ} \mathrm{C}, 42^{\circ} \mathrm{C}, 47^{\circ} \mathrm{C}, 52^{\circ} \mathrm{C}$, or $57^{\circ} \mathrm{C}$ for $5 \mathrm{~min}$ and then $\mathrm{r}^{\circ}$ vered an $7^{\circ} \mathrm{C}$. The MTT assay showed a decline in cell viability after a 5-min exposure to ted temperatures $\left(47^{\circ} \mathrm{C}, 52^{\circ} \mathrm{C}\right.$, and $57^{\circ} \mathrm{C}$ ) at $12 \mathrm{~h}, 1$ day, 2 days, and 5 days $\mathrm{p}$ trea t. Treatment at $42{ }^{\circ} \mathrm{C}$ had no obvious effect on cell viability. However, trea no ${ }^{\circ}$ or $57{ }^{\circ} \mathrm{C}$ resulted in low cell viability throughout all of the time points tested inhalation injury has been reported to be approximately 48. at the bronchi [19]. Thus, treatment at $47^{\circ} \mathrm{C}$ was close to the pathophysio al situation inhalation injury [20]. We observed that after $47^{\circ} \mathrm{C}$ treatment for $5 \mathrm{~min}$, the viability decreased from day 1 to day 4 and increased back to control levels at day 5 (Fi ر g ig. 1C, as shown by TUNEL staining, a significantly increased number of cells und ent sptosis $12 \mathrm{~h}$ after heat treatment, with the highest level on day 1 and a retum to sal level on day 5 . The expression of apoptosis-related proteins, including $\mathrm{P} \quad \mathrm{A}$, x cleaved PARP, and cleaved caspase-3, was markedly increased as well (Fig 1D).

Protective effects of curcur qinst neat-induced apoptosis in vitro

Curcumin is a plant-derived c ind shown to protect cells from apoptosis through different pathways [11]. y oceedea to test whether curcumin exerted a protective effect on heat-induced apopto in 1 3E140 cells. The cells were treated with curcumin (10 or $20 \mu \mathrm{mol} / \mathrm{L}) 4 \mathrm{~h}$ before or and apoptosis we nirrcu. As shown in Fig. $2 \mathrm{~A}$ and $2 \mathrm{~B}$, cell viability was increased, and the number of ${ }^{\prime} \mathrm{N}^{-}$tive cells decreased significantly in both the curcumin pre-and post-treatm $t$ gr ps compared to that of the control group. In addition, Western blot analysis s ed th ells treated with curcumin showed significantly decreased expression of Parele. and cleaved caspase-3 and increased expression of Bcl2 compared to th. he co $\mathrm{s}$ group (Fig. 2C).

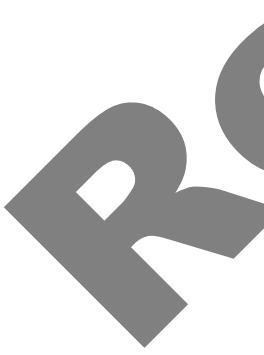

Cun in decreased heat-induced ROS generation by inhibiting membrane translocation NADPH oxidase 2 cytosolic subunits ecause Ros was involved in the heat-induced apoptosis and NADPH oxidase 2 is the nary source of Ros, we tried to determine whether curcumin treatment alleviated heatinduced apoptosis via inhibiting NADPH oxidase 2/ROS production. DCF-DA fluorescence staining revealed that intracellular ROS increased after heat treatment, peaked on day 1 and returned to normal on day 5 (Fig. 3A). Levels of 4-hydroxynonenal and nitrotyrosine, which are oxidative modification proteins partially produced by superoxide or ROS formation, were also examined by ELISA. Both 4-hydroxynonenal and nitrotyrosine showed a similar changing pattern as that of ROS (Fig. 3B). Moreover, we found that heat-induced ROS generation and the expression of superoxide signal proteins were markedly decreased by curcumin administration, pre- or post- heat treatment (Fig. 3C and 3D). Furthermore, as shown by Western blot analysis, heat treatment significantly increased the expression 


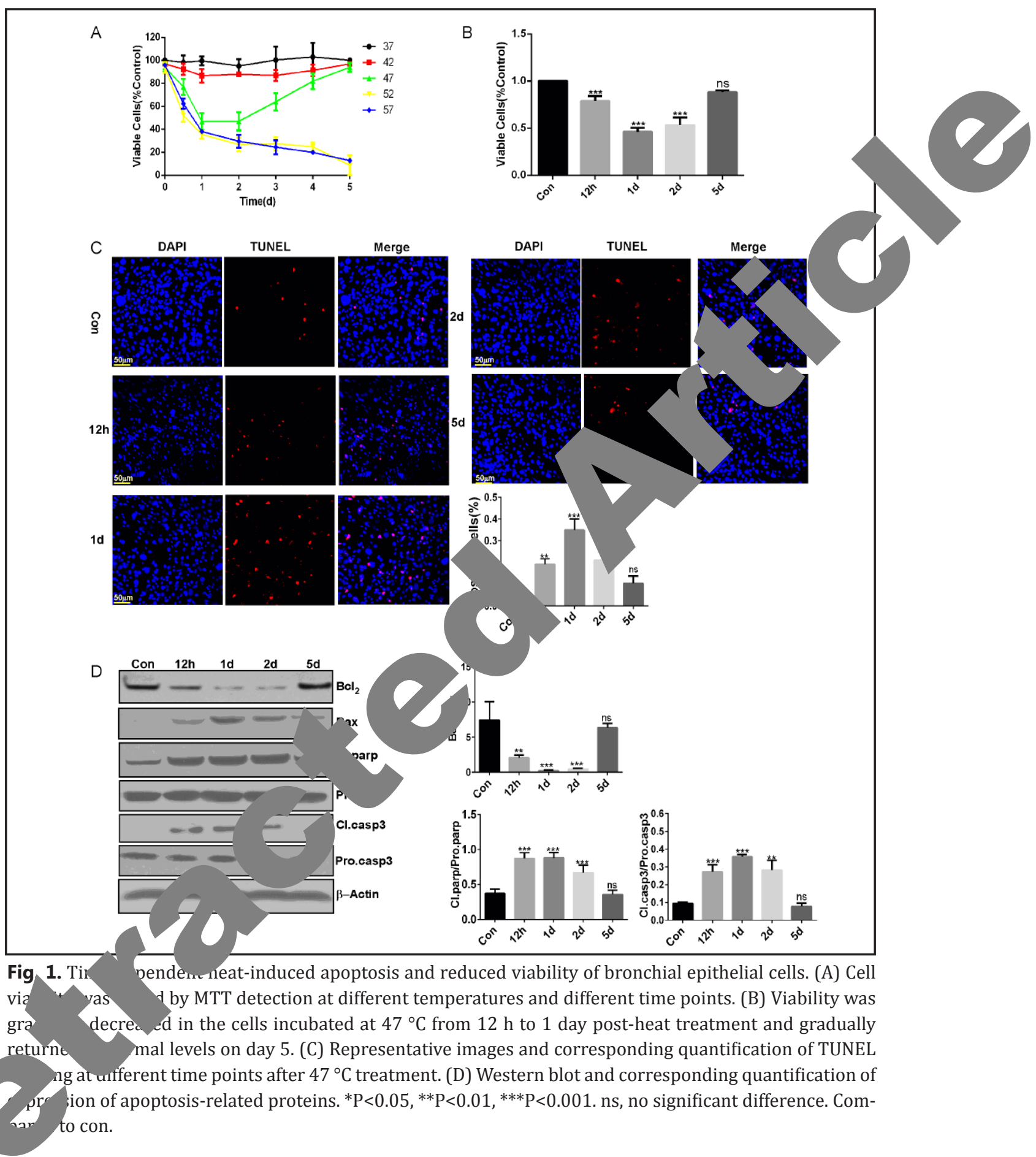

of Rac, p47 phox, $\mathrm{p} 40^{\text {phox }}$, and p67 $7^{\text {phox }}$ in the cellular membrane on day 1 , and the expression returned to basal levels on day 5 (Fig. 3E). The expression of cytosolic subunits decreased to almost control levels in both the curcumin treatment group as well as the NADPH oxidase 2 inhibitor DPI and orgp91ds-tat treatment groups. A similar trend was observed in the MPG treatment group, which is known as a ROS scavenger (Fig. 3F). DPI, gp91ds-tat, or MPG treatment also markedly inhibited apoptosis, as indicated by the decreased expression of Bax, cleaved PARP, and cleaved caspase-3 (Fig. 3G). To further explore the role of NADPH oxidase 2 in heat-induced apoptosis, NADPH oxidase 2 siRNA (Nox2 siRNA) was used to downregulate the expression of NADPH oxidase 2 (Fig. 3H). As shown by Western blot 


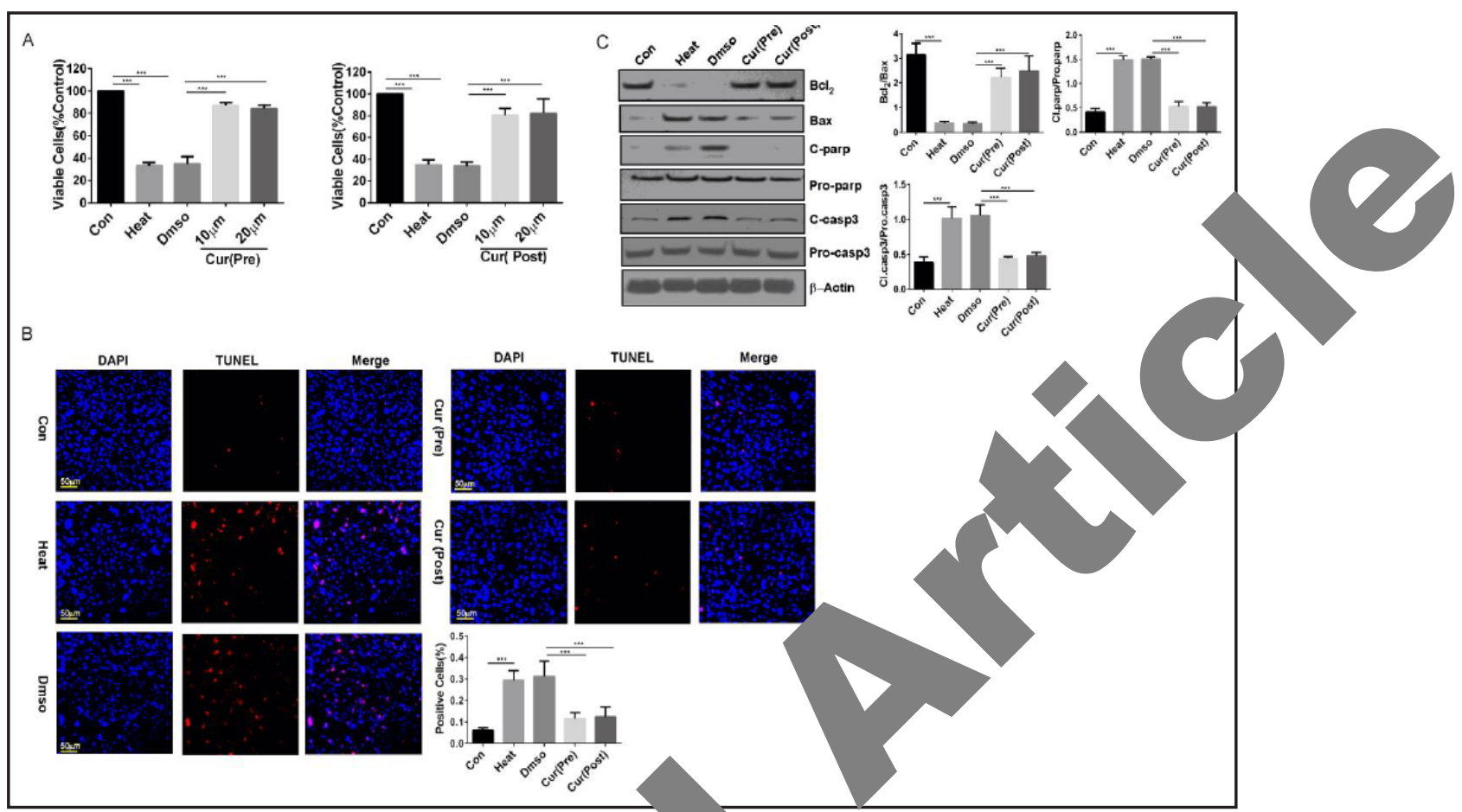

Fig. 2. Protective effects of curcumin against heat-induce tosis in vitro. (A) 16HBE140 cells after curcumin treatment were analyzed for cell viability by M assa. Representative images and corresponding quantification of TUNEL staining 1 day after curc that pre- or post-treatment with curcumin att the 15 of apoptosis markers. ${ }^{*} \mathrm{P}<0.05,{ }^{* *} \mathrm{P}<0.01$, $* * * \mathrm{P}<0.001$. Compared to con or DMSO treat nt

analysis, downregulation of 1 markers, suggesting an inhibi apoptosis (Fig. 3I). These results demonstrated that inhibition of the membrane tmaslo of NADPH oxidase 2 cytosolic components and Ros production is involved in anti-apoptosis effect of curcumin in heat treatment.

Curcumin protocted. signaling $p o$ om heat-induced apoptosis by activating the Akt/mTOR Akt/mTOF gr Akt/mTOR as $;$ ed in the mechanism by which curcumin inhibits heat-induced apoptosi e res aemonstrated that the levels of phosphorylated AKT at both the Thr308 an $S \cdot 4\rangle$ s significantly decreased on day 1 and day 2 and were recovered on day 5 (F . Con ering that Akt at Thr308 binds to the phosphoinositide-dependent protein kinus xp sion of PDK1 and mTOR after heat treatment. Western blot showed that levels of P K1 phosphorylated mTOR (Ser2448) and mTOR (Ser2481) significantly decreased on ar and day 2 (Fig. 4A). As we excepted, curcumin pre- or post-heat treatment markedly egulated phosphorylated Akt at the Ser473 and Thr308 sites, as well as phosphorylated mTOR at the Ser2448 and Ser2481 sites, along with expression of PDK1. These effects of curcumin were similar to those of IGF-1, a specific Akt activator (Fig. 4B and 4D). In addition, IGF-1 or Mhy1485 abolished the apoptosis induced by heat treatment as indicated by the expression of apoptosis markers (Fig. 4C).

As both NADPH oxidase 2 and Akt/mTOR have been demonstrated to be involved in the mechanism of curcumin inhibiting cell apoptosis induced by heat, we proceeded to explore whether there was crosstalk between these two signaling pathways. Treatment with the NADPH oxidase inhibitor DPI or the gp91 ${ }^{\text {phox }}$ inhibitor gp91ds-tat significantly upregulated the phosphorylation level of both PDK1/Akt and mTOR, as shown by Western blot analysis 
Fig. 3. Curcumin decreases heat-induced ROS generation by inhibiting membrane translocation of NADPH oxidase 2 cytosolic components. (A) ROS production was detected by DCFDA fluorescence at different time points after heat treatment. (B) Expression levels of 4-hydroxynonenal (4-HNE) and nitrotyrosine (NT) were tested by ELISA at different time points after heat treatment. (C) ROS production was detected by DCFDA fluorescence after curcumin treatment. (D) 4-HNE and NT production was detected by ELISA after curcumin treatment. (E) Representative Western blot showing the trend of the expression of NADPH oxidase subunits in cells incubated at $47^{\circ} \mathrm{C}$ at different time points post-treatment. (F) Western blot analysis showing that curcumin treatment, NADPH oxidase inhibitor DPI treatment, gp91ds-tat treatment, and ROS scavenger MPG treatment reversed the heat-induced increase if the membrane-bound cyto solic subunits. (G) blot analysis she nq NADPH oxid $\mathrm{e}$ ir bit DPI, gp91 it, an os sca ngro treatments att d th spression of a.p ic markers. (H) $\mathrm{R}$ à sis was perfor(f) t analyze the expresion vels of Nox2. (I) Wesblot analysis showing that Nox2 siRNA attenuated the expression of apoptosis markers. ${ }^{*} \mathrm{P}<0.05$, ${ }^{* *} \mathrm{P}<0.01$, $* * * \mathrm{P}<0.001$. ns, no significant difference. Compared to con or DMSO treatment.
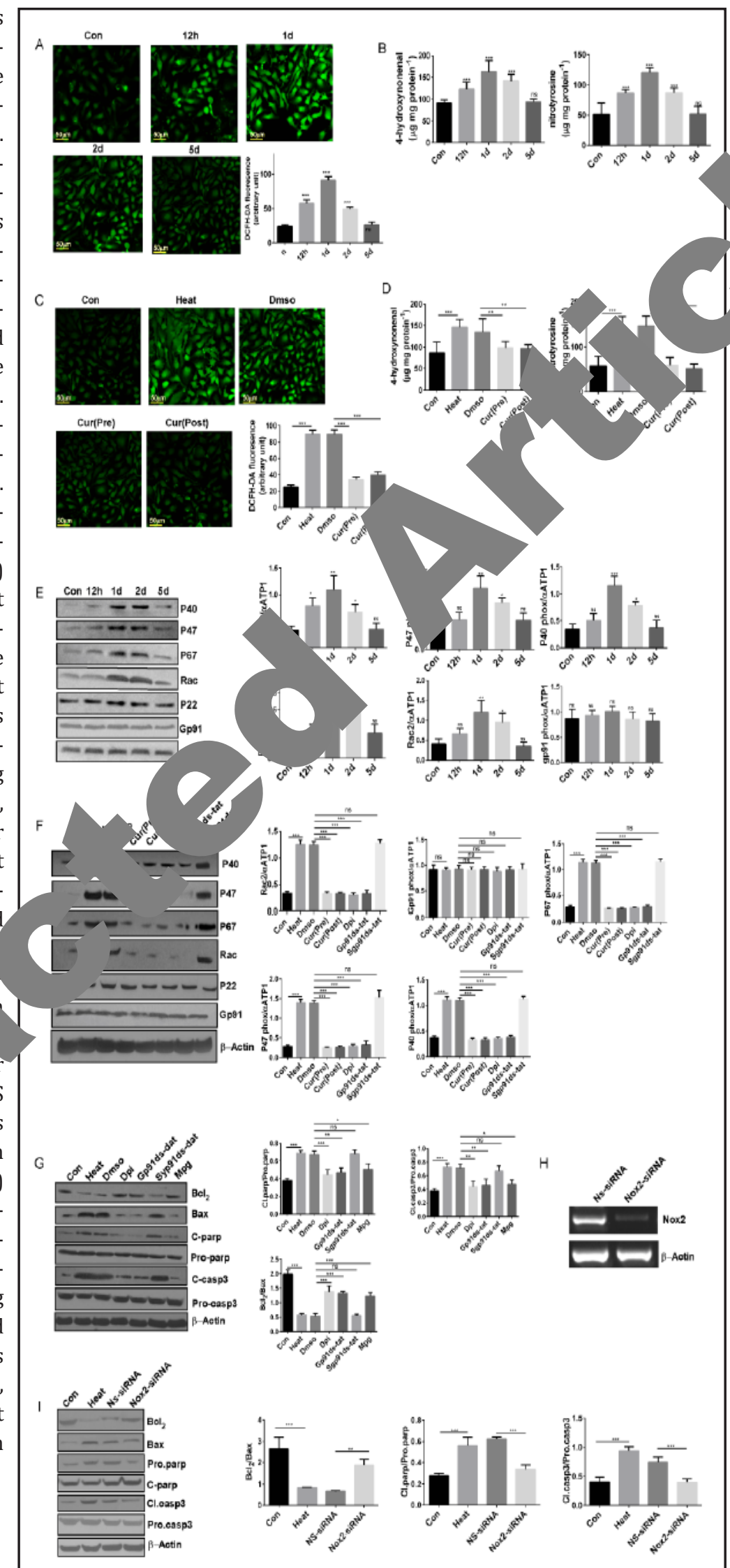
Fig. 4. Curcumin exerts a protective effect against heat-induced apoptosis by activating the Akt/ mTOR signaling pathway. (A) Expression levels of Ser473 and Thr308 phospho-Akt, total Akt, Ser2448 and Ser2481 phospho-mTOR, PDK1 and total mTOR proteins are shown at different time points after heat treatment. (B) Western blot analysis showing a modest increase in both Akt and mTOR phosphorylation and PDK1 in response to curcumin pre-treatment and post-treatment. (C) Western blot analysis showing that IGF treatment and Mhy1485 attenuated the overexpression of apoptosis markers (compared to DMSO treatment). (D) Western blot analysis showing the change in Akt and mTOR expression after DPI, gp91dstat, sgp91ds-tat and Akt activator IGF treatment (vs. DMSO treatment). (E) Western blot an showing the cha
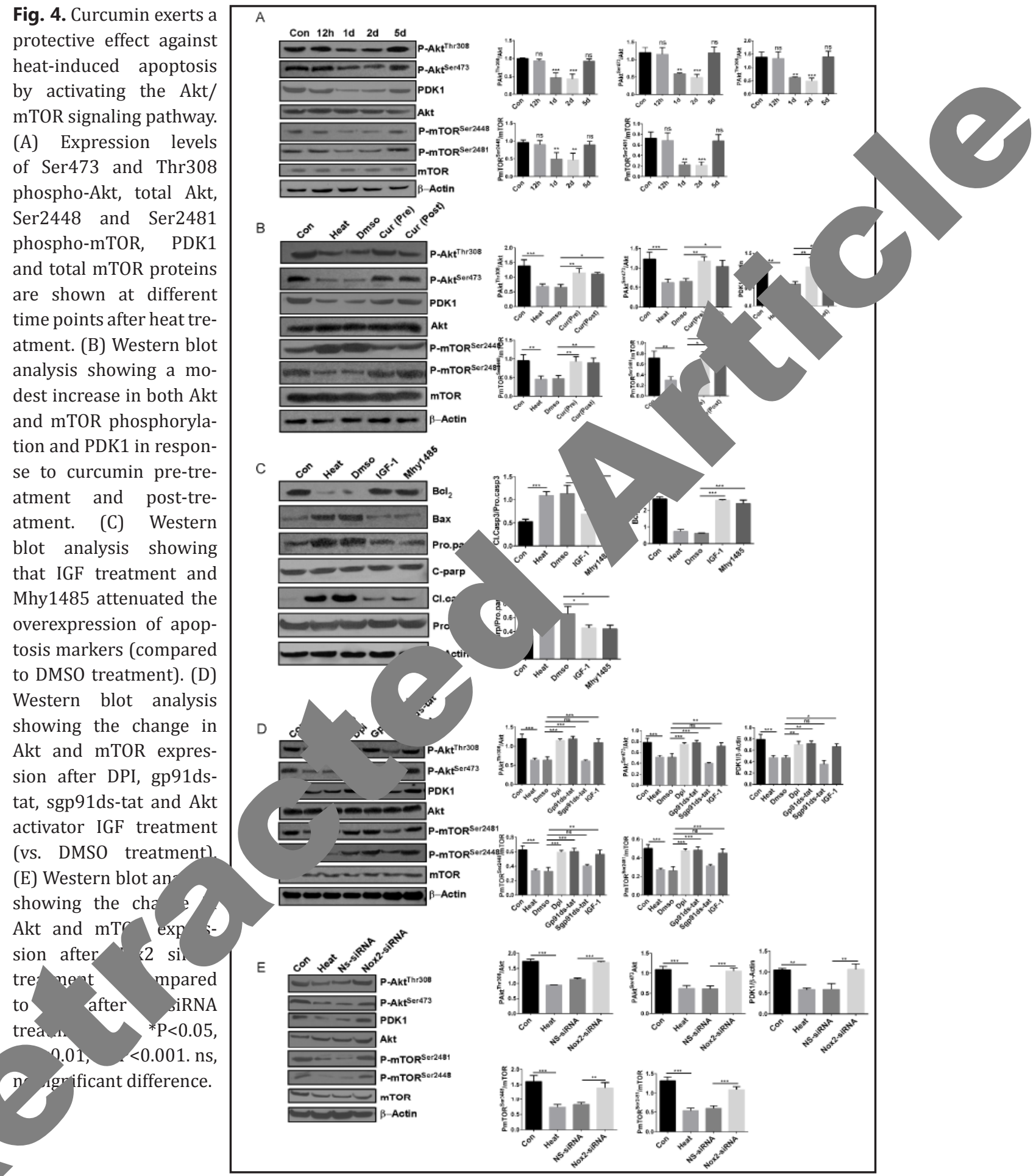

(Fig. 4D). As excepted, knockdown of Nox2 with siRNA had a similar effect as the NADPH oxidase inhibitor (Fig. 4E). These results suggested that NADPH oxidase 2 is upstream of Akt/ mTOR signaling in heat-induced apoptosis, and the NADPH oxidase 2/Akt/mTOR signaling pathway was involved in the inhibition of heat-induced apoptosis by curcumin.

\section{Anti-apoptosis activity of curcumin in a rat model of thermal inhalation injury}

Heat-induced bronchial epithelia apoptosis and the anti-apoptosis effect of curcumin were also tested in vivo by taking advantage of a rat model of thermal inhalation injury. In the KARGER 


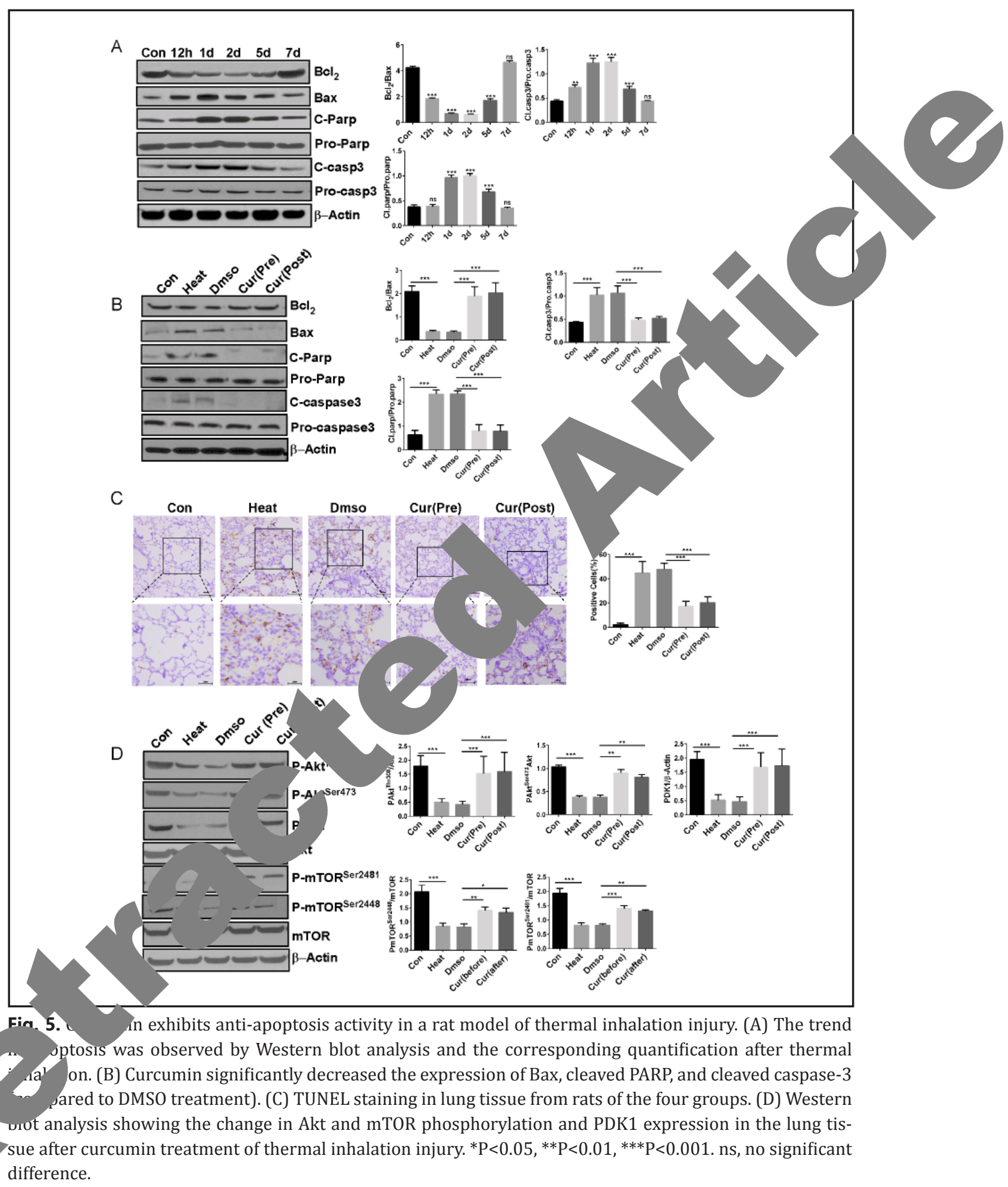

animal model, the temperature of the air from the heat gun is approximately $800{ }^{\circ} \mathrm{C}$ and is cooled down to approximately $48^{\circ} \mathrm{C}$ at the bronchi, which is consistent with the temperature used in vitro. The lung tissue was harvested for Western blot and TUNEL staining. The expression of apoptosis-related proteins in lung tissue increased on day 1 , peaked on day 2 , and then gradually decreased on day 7 after heat treatment (Fig. 5A). Curcumin strikingly 


\section{Cellular Physiology \begin{tabular}{l|l} 
and Biochemistry Published online: April 19, 2017 & $\begin{array}{l}\text { (c) 2017 The Author(s). Published by S. Karger AG, Basel } \\
\text { www.karger.com/cpb }\end{array}$ \\
\hline
\end{tabular} \\ Peng et al.: Curcumin Alleviates Heat-Induced Apoptosis of $16 \mathrm{HBE} 140$ Cells In Vitro and In Vivo}

Fig. 6. Curcumin exerts a protective effect against heat-induced apoptosis by activating the Akt/mTOR signaling pathway.

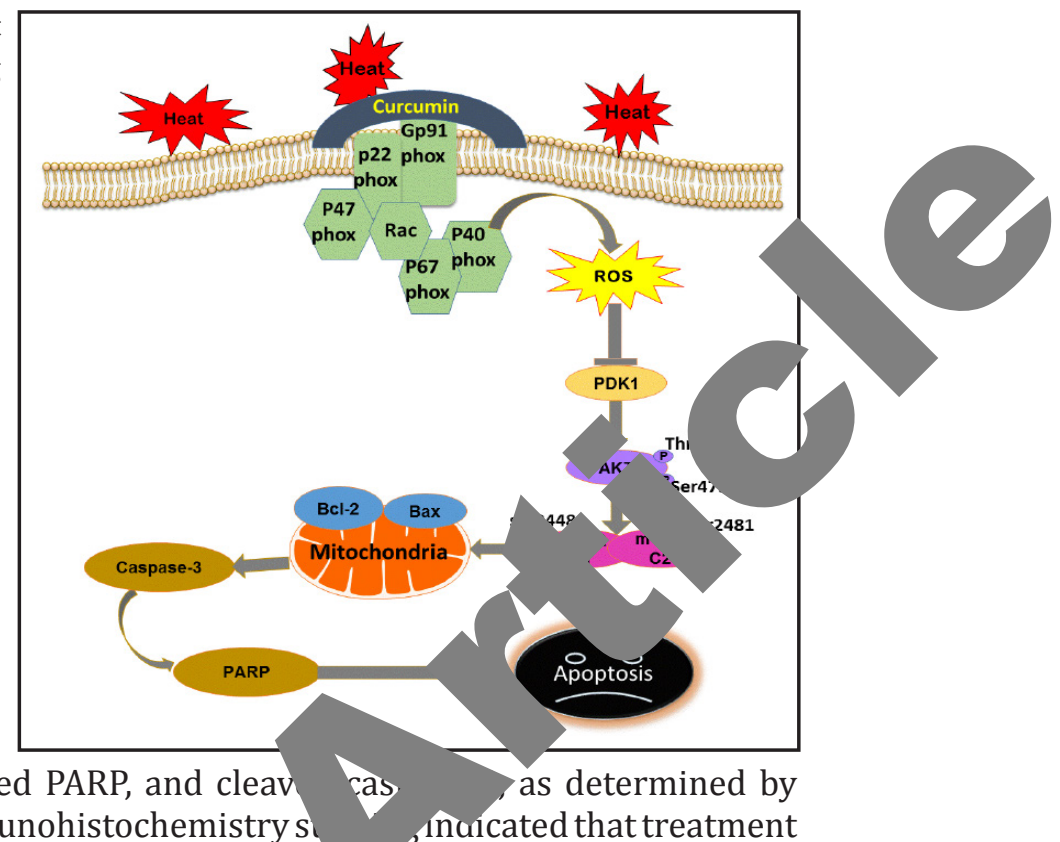

decreased the expression of Bax, cleaved PARP, and cleav cas as determined by
Western blot (Fig. 5B). Consistently, immunohistochemistry s with curcumin significantly reduced apoptotic cells after heat tment (Fig. 5C). As shown in Fig. 5D, heat reduced the expression of phe rylated Ak at the Ser473 and Thr308 sites, phosphorylated mTOR at the Ser2448 and St 1 sites and PDK1. However, curcumin treatment reversed the decrease back to norm ¿Ve hese results demonstrated that the Akt/mTOR signaling pathway was inhibited $r$ t nal inhalation and activated after curcumin treatment in vivo.

\section{Discussion}

This study investigated th obtained several major findinos, Fis

of curcumin in inhibiting heat-induced apoptosis and atment with curcumin significantly alleviated heatinduced apoptosis and in wed cell viability. Second, curcumin administration, both pre- or post- heat treatment, $\mathrm{m}$ kedly hibited the membrane translocation of NADPH oxidase 2 cytosolic components, esulted in a reduction in ROS generation and alleviated apoptosis after $\mathrm{h} r$ tmen. Third, the Akt/mTOR signaling pathway was implicated in the inhibition of he in a ronchial epithelia apoptosis by curcumin. Lastly, NADPH oxidase 2 was found be st am of Akt/mTOR signaling in heat-induced apoptosis. Briefly, these results $\mathrm{d} c$ nstra at curcumin alleviated heat-induced apoptosis by inhibiting NADPH ox ' 5 2. tion and upregulating the Akt/mTOR signaling pathway.

erma ury of the airway caused by heated air is a leading cause of burn-related dean 1 However, the hot air is cooled down to approximately $48.3^{\circ} \mathrm{C}$ by the time it hes bronchi airway because over $90 \%$ of the heat is released in the upper airway (1) 1. has been reported that high temperatures (those above $43^{\circ} \mathrm{C}$ ) can cause pathological na ,es and affect cell functions [23]. Therefore, the experimental condition of $47{ }^{\circ} \mathrm{C}$ for 5 was employed to treat cells in all in vitro experiments (designated as heat treatment), which is relevant to the pathological situation in thermal injury. Our results demonstrated that the heat treatment condition could induce apoptosis in 16HBE140 cells.

Apoptosis is one of the most important pathogenic mechanisms underlying heatinduced bronchial epithelial cell damage [24]. Reactive oxygen species (ROS) are well-known oxygen radicals that lead to oxidative stress and apoptosis [25]. ROS are rapidly produced and accumulate when cells suffer from injury, and ROS overloading leads to irreversible cellular apoptosis [26]. Consistent with these reports, we also observed that heat treatment induced ROS production, which resulted in apoptosis. Furthermore, curcumin was found to be able to reduce ROS production, thus inhibiting cell apoptosis. 


\section{Cellular Physiology

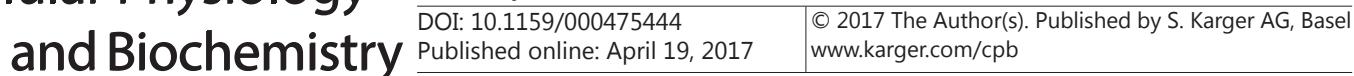 \\ Peng et al.: Curcumin Alleviates Heat-Induced Apoptosis of 16HBE140 Cells In Vitro and

This study demonstrates the role of NADPH oxidase 2 cytosolic subunits in mediating heat-induced apoptosis. NADPH oxidase 2 is an enzymatic compound that catalyzes ROS bio-synthesis. In our study, cells treated with heat showed upregulated p47phox and p67phox levels in the cell membrane. Both inhibition of NADPH oxidase 2 with an inhibitor and knockdown with siRNA suppressed heat-induced cell apoptosis. In addition, curcumin treatment markedly decreased p47phox and p67phox expression and NADPH oxidas 2 activation, thus inhibiting apoptosis. Collectively, these results indicate that curcumi protects bronchial epithelial cells from heat-induced apoptosis by regulating the membrane translocation of NADPH.

This study has demonstrated that Akt/mTOR signaling plays a part in heat-ir apoptosis. Akt/mTOR has been identified to play a principal role in the signaling pathway in different cell apoptosis models caused by extracellular or signaling $[27,28]$. In the present study, we found that activation of $\mathrm{Ak}$ was inhibited by heat. Curcumin has been reported to have potent an antimetastasis effects on various cancers by suppressing Akt/m? However, in our study, curcumin treatment markedly upregulated $\mathrm{p}^{\wedge}$ Shorylaved Akt and mTOR. This inconsistency may be due to different cell typos and $t$. vents, suggesting a cell- and tissue-specific effect of curcumin in the regul the A. MTOR signaling pathway, although the underlying mechanism still needs the tigation. However, the mechanism by which curcumin actives Akt/mTOR in hec ceu apoptosis still needs to be illuminated. Curcumin has been reported to have a bro ange of molecular targets. Therefore, some other pathways in addition to Akt/mTOR athway may be involved in curcumin suppressing heat-induced cell apoptos.

mTOR activation in bronchial epithelial ce injury, which is consistent with our results th in the apoptosis of the heat-treated cello arthermore, in our study, treatment with a NADPH oxidase 2 inhibitor or $\mathrm{k} c \mathrm{ck}$ wn of NADPH oxidase 2 induces activation of Akt/mTOR signaling, indicating that 1 dase 2 is upstream of Akt/mTOR. Of note, S6K1, S6 and 4E-BP1 are dow $\quad R$, regulating cell motility. S6K1 and S6 have been considered to regulate ar is, the cell cycle and metabolism [32]. 4EBP1 plays an important role in protein synthesis, cowth and cell proliferation [33]. Thus, the effect of curcumin inhibiting heat aced apoptosis may be mediated by these molecules.

Collectively, this stu has constrated that curcumin inhibits heat-induced apoptosis, and the underlying mec. signaling pathwa mons (rated in Fig. 6). Thus, regulation of this pathway in pulmonary epithelial cells thermal inh tror $\mathcal{O}$

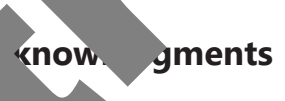

Th. ady was supported by the grant of the Natural Science Foundation of Chongqing, (No. cstc2015shmszx120019).

\section{Disclosure Statement}

The authors declare no conflicts of interests

\section{References}

1 Chen J, Yan H, Luo G, Luo Q, Li X, Zhang J, Yuan Z, Peng D, Peng Y, Hu J, Wu J: Characteristics of burn deaths from 2003 to 2009 in a burn center: A retrospective study. Burns Trauma 2013;1:80-86. 


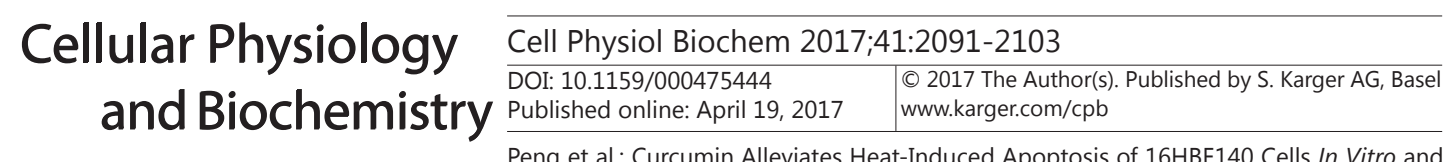
In Vivo

2 Roberts GT, Ghebeh H, Chishti MA, Al-Mohanna F, El-Sayed R, Al-Mohanna F, Bouchama A: Microvascular injury, thrombosis, inflammation, and apoptosis in the pathogenesis of heatstroke: a study in baboon model. Arterioscl Throm Vas 2008;28:1130-1136.

- 3 Gu ZT, Wang H, Li L, Liu YS, Deng XB, Huo SF, Yuan FF, Liu ZF, Tong HS, Su L: Heat stress induces apoptosis through transcription-independent p53-mediated mitochondrial pathways in human umbilical vein endothelial cell. Sci Rep 2014;4:4469.

- 4 Isaksen TB, Yost MG, Hom EK, Ren Y, Lyons H, Fenske RA: Increased hospital admissions associated with extreme-heat exposure in King County, Washington, 1990-2010. Rev Environ Health 2015;30:51-64. Cheng CH, Yang FF, Liao SA, Miao YT, Ye CX, Wang AL, Tan JW, Chen XY: High temperature induces apor and oxidative stress in pufferfish (Takifugu obscurus) blood cells. J Therm Biol 2015;53:172-179. Lee SJ, Yang ES, Kim SY, Kim SY, Shin SW, Park JW: Regulation of heat shock-induced apop to apoptosis gene protein. Free Radical Bio Med 2008;45:167-176. Ther Ex 2012;60:277-294.

Thompson SM, Callstrom MR, Jondal DE, Butters KA, Knudsen BE, Anderson JL, Lie Thorgeirsson SS, Grande JP, Roberts LR, Woodrum DA: Heat Stress-Induced PI3 Signaling Is a Central Mediator of Hepatocellular Carcinoma Survival to Therma Stress. PloS one 2016;11:e0162634. Kim SY, Gul R, Rah SY, Kim SH, Park SK, Im MJ, Kwon HJ, Kim UH: M cyclase activation in angiotensin II signaling in murine mesangial cel 2008;294:F982-989.

10 Dai C, Li D, Gong L, Xiao X, Tang S: Curcumin Amelior Apoptosis in Human Hepatocyte L02 Cells by Inhibiting Production and Mitochondrial Pathway. Molecules DOI:10.3390/molecules21081061.

11 Zheng KM, Zhang J, Zhang CL, Zhang YW, Chen XC: upregulating heme oxygenase-1 expression i

12 Huang SL, Chen PY, Wu MJ, Tai MH, Ho CT, Reactive Oxygen Species Signaling Pathw Differentiation. J Agr Food Chem

13 Jiao D, Wang J, Lu W, Tang X, Che angiogenesis through regulatino c-M dent PI3K/Akt/mTOR signaling pathways in lung cancer. Mol Ther Oncolytics 2016;3:1

14 Roti Roti JL: Cellular res ses to perthermia $\left(40-46^{\circ} \mathrm{C}\right)$ : Cell killing and molecular events. Int J Hyperther 2008;24:3-15

15 Dong ZW, Chen C, Lruu T, Chen Y, Chen Y, Tsang LL, Chan HC, Peng YZ: CFTR-regulated MAPK/NFkappaB signa $a_{\text {a }}$ ary inflammation in thermal inhalation injury. Sci Rep 2015;5:15946.

16 Li W, Liu Lin D IX Lu H, Bi X, Wang M: Low Expression of Polo-like Kinase 1 is Associated with Poor Proge In Live icer. Cancer Transl Med 2015;1:196-200.

17 Cbung 17 , Xing H, Carroll RS, Johnson MD: miR-505 Downregulates 6-Phosphofructo-2-Kinase/ ctose-_ phosphatase 4 to Promote Cell Death in Glioblastoma. Cancer Transl Med 2015;1:158-165.

18 Freeman MR, Long E, Thompson MA, Pabelick CM, Prakash YS. Cigarette Smoke and Estrogen Sigh o in Human Airway Smooth Muscle. Cell Physiol Biochem 2015;36:1101-1115.

1. Murillo MM, Carmona-Cuenca I, Del Castillo G, Ortiz C, Roncero C, Sanchez A, Fernandez M, Fabregat I: ctivation of NADPH oxidase by transforming growth factor-beta in hepatocytes mediates up-regulation of epidermal growth factor receptor ligands through a nuclear factor-kappaB-dependent mechanism. Biochem J 2007;405:251-259.

Rong YH, Liu W, Wang C, Ning FG, Zhang GA: Temperature distribution in the upper airway after inhalation injury. Burns 2011;37:1187-1191.

-21 Hao Y, Cheung CS, Yip WC, Ko WH: Nobiletin Stimulates Chloride Secretion in Human Bronchial Epithelia via a cAMP/PKA-Dependent Pathway. Cell Physiol Biochem 2015;37:306-320.

22 Suzuki T, Hirayama T, Aihara K, Hirohata Y: Experimental studies of moderate temperature burns. Burns 1991;17:443-451. 


\section{Cellular Physiology Cell Physiol Biochem 2017;41:2091-2103}

\begin{tabular}{l|l} 
DOI: 10.1159/000475444 & and Biochemistry \\
Published online: April19, 2017 & $\begin{array}{l}\text { 2017 The Author(s). Published by S. Karger AG, Basel } \\
\text { www.karger.com/cpb }\end{array}$
\end{tabular}

Peng et al.: Curcumin Alleviates Heat-Induced Apoptosis of 16HBE140 Cells In Vitro and In Vivo

23 Wang JP, Yu YC, Chen SP, Liang HC, Lin CW, Fang K: The collective nuclear migration of p53 and phosphorylated S473 of Akt during ellipticine-mediated apoptosis in human lung epithelial cancer cells. Mol Cell Biochem 2015;407:123-133.

24 Lv YG, Liu J, Zhang J: Theoretical evaluation of burns to the human respiratory tract due to inhalation of hot gas in the early stage of fires. Burns 2006;32:436-446.

25 Wang L, Wu G, Qin X, Ma Q Zhou Y, Liu S, Tan Y: Expression of Nodal on Bronchial Epithelial Cells Influenced by Lung Microbes Through DNA Methylation Modulates the Differentiation of T-Helper Cells. Cell Physiol Biochem 2015;37:2012-2022.

-26 Moench R, Grimmig T, Kannen V, Tripathi S, Faber M, Moll EM, Chandraker A, Lissner R, Germer CT, W Gasser AM, Gasser M: Exclusive inhibition of pi3k/akt/mtor signaling is not sufficient to prevent pd mediated effects on glycolysis and proliferation in colorectal cancer. Oncotarget 2016;7:69 -687

27 Han SG, Castranova V, Vallyathan V: Comparative cytotoxicity of cadmium and mercury in a bronchial epithelial cell line (BEAS-2B) and its role in oxidative stress and induction sh 70. J Toxicol Environ Health A 2007;70:852-860.

-28 Redza-Dutordoir M, Averill-Bates DA: Activation of apoptosis signalling pathways species. Biochim Biophys Acta 2016;1863:2977-2992.

29 Xu L, He S, Yin P, Li D, Mei C, Yu X, Shi Y, Jiang L, Liu F: Punicalagin indures Nrf2 t. expression via PI3K/Akt, protecting rat intestinal epithelial cells $\mathrm{fr}$ ive stro it J Hyperthermia 2016;32:465-473.

-30 Ramakrishnan V, Gomez M, Prasad V, Kimlinger T, Painuly U, Mukhop Kumar S: Smac mimetic LCL161 overcomes protective ER stress induc causing cell death in multiple myeloma. Oncotarget 2 7:56253-562 , Huug J, Bi L, Rajkumar SV, obatoclax, synergistically

-31 Sintara K, Thong-Ngam D, Patumraj S, Klaikeaw N, Cha activation and macromolecular leakage in Helicobac 2010;16:4039-4046.

-32 Hu Y, Lou J, Mao YY, Lai TW, Liu LY, Zhu C, Zhan - Lil. fected rats. World J Gastroenterol Activation of MTOR in pulmonary epitheli pr stes LPS-induced acute lung injury. Autophagy 2016:114.

33 Yu G, Zeng X, Wang H, Hou Q, Ta smoke extract-induced apoptosi Physiol Biochem 2015;36:474-486.

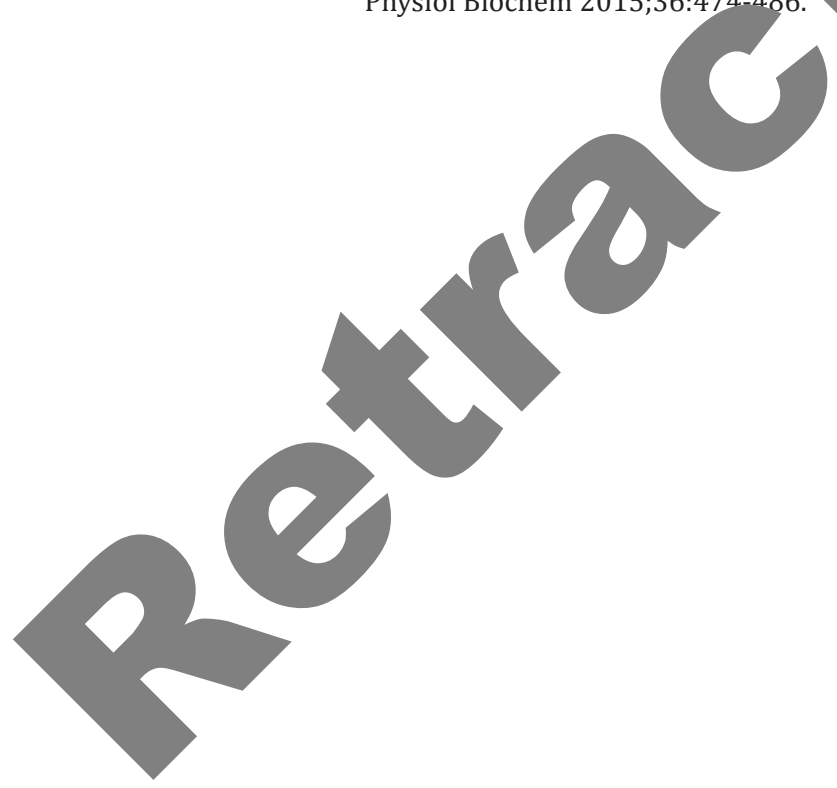

